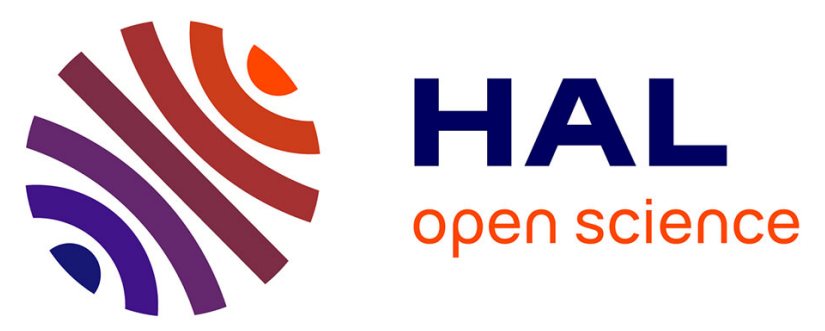

\title{
Association of baseline symptom burden with efficacy outcomes: Exploratory analysis from the randomized phase III REVEL study in advanced non-small-cell lung cancer
}

Maurice Pérol, Katherine B. Winfree, Gebra Cuyun Carter, Zhanglin Lin Cui, Lee Bowman, Edward B. Garon

\section{To cite this version:}

Maurice Pérol, Katherine B. Winfree, Gebra Cuyun Carter, Zhanglin Lin Cui, Lee Bowman, et al.. Association of baseline symptom burden with efficacy outcomes: Exploratory analysis from the randomized phase III REVEL study in advanced non-small-cell lung cancer. Lung Cancer, 2019, 131, pp.6 - 13. 10.1016/j.lungcan.2019.03.001 . hal-03485652

\section{HAL Id: hal-03485652 \\ https://hal.science/hal-03485652}

Submitted on 20 Dec 2021

HAL is a multi-disciplinary open access archive for the deposit and dissemination of scientific research documents, whether they are published or not. The documents may come from teaching and research institutions in France or abroad, or from public or private research centers.
L'archive ouverte pluridisciplinaire HAL, est destinée au dépôt et à la diffusion de documents scientifiques de niveau recherche, publiés ou non, émanant des établissements d'enseignement et de recherche français ou étrangers, des laboratoires publics ou privés.

\section{(ㅇ)(1) $\$$}

Distributed under a Creative Commons Attribution - NonCommerciall 4.0 International 
Association of Baseline Symptom Burden With Efficacy Outcomes: Exploratory Analysis From the Randomized Phase III REVEL Study in Advanced Non-Small-Cell Lung Cancer

${\text { Maurice Pérol }{ }^{a} \text {, Katherine B. Winfree }}^{b}$, Gebra Cuyun Carter ${ }^{b}$, Zhanglin Lin Cui ${ }^{b}$, Lee Bowman ${ }^{b}$, Edward B. Garon ${ }^{c}$

aDépartement de Cancérologie Médicale Centre Léon-Bérard, Lyon, France; 'bli Lilly and Company, Indianapolis, IN, USA; ${ }^{C D a v i d}$

Geffen School of Medicine at UCLA/Translational Research in Oncology-US Network, Los Angeles, CA, USA

Corresponding author:

Maurice Pérol

Département de Cancérologie Médicale Centre Léon-Bérard

28 rue Laennec

Lyon, France

Fax: + 33478782716

E-mail address: maurice.perol@lyon.unicancer.fr 


\section{ABSTRACT}

Objectives: The REVEL study demonstrated improved efficacy with ramucirumab plus docetaxel versus placebo plus docetaxel for previously treated advanced/metastatic non-small-cell lung cancer (NSCLC) without further detriment to patient quality of life, symptoms, or functioning. This post hoc analysis explored the association between baseline Lung Cancer Symptom Scale (LCSS) Average Symptom Burden Index (ASBI) and efficacy.

Materials and Methods: Baseline ASBI scores were the average of the 6 LCSS symptom components. Low and high symptom burden (LSB $\leq$ median, HSB >median) were analyzed across and by treatment arms for effects on overall survival (OS), progressionfree survival (PFS), and objective response rate (ORR) using the Kaplan-Meier method and Cox proportional hazards model.

Results: Baseline LCSS compliance was approximately $78 \%$ in both REVEL treatment arms. Patients with LSB versus HSB had fewer poor prognostic factors. The HSB patient population significantly overlapped with previously identified aggressive disease subgroups (rapidly progressing disease or refractory to first-line treatment). Patients with LSB versus HSB had significantly improved OS $(P<0.0001)$, PFS $(P<0.0001)$, and ORR $(P=0.0003)$ regardless of treatment, with superior ORR and PFS but not OS in the ramucirumab plus docetaxel arm. Patients with HSB treated with ramucirumab plus docetaxel versus docetaxel had improved OS (median, 7.39 vs. 5.95 months; HR 0.749 [95\% Cl 0.610-0.920]; $P=0.0308$ ), PFS (median, 4.01 vs. 2.63 months; HR 0.749 [0.6190.907]; $P=0.0202)$, and ORR (18\% vs. 11\%; $P=0.0458)$. Of patients with rapidly progressing disease, 57\% (92/162) also had HSB. 
Conclusions: Baseline ASBI may be an independent prognostic factor in this large second-line cohort of patients with advanced NSCLC. The preservation of improved PFS and OS in the HSB cohort suggests that the addition of ramucirumab to docetaxel provides benefit in patients with greater symptom burden, consistent with previous data on REVEL patients with aggressive disease.

Keywords: ramucirumab, quality of life, lung cancer, survival, symptom burden

Abbreviations: ASBI, Average Symptom Burden Index; $\mathrm{Cl}$, confidence interval; CR, complete response; DCR, disease control rate; ECOS PS, Eastern Cooperative Oncology Group performance status; HR, hazard ratio; ITT, intent-to-treat; LCSS, Lung Cancer Symptom Scale; NSCLC, non-small-cell lung cancer; OR, odds ratio; ORR, objective response rate; OS, overall survival; PD, progressive disease; PFS, progression-free survival; PR, partial response; QoL, quality of life; SD, stable disease 


\section{INTRODUCTION}

Non-small-cell lung cancer (NSCLC) continues to be one of the most commonly diagnosed and lethal cancers worldwide. Approximately $70 \%$ of patients are diagnosed with late-stage disease, and the 5 -year survival rate for stage IIIB/IV NSCLC is $5 \%$ $[1,2]$. Regardless of treatment, patients with advanced or metastatic NSCLC at diagnosis will likely experience disease progression after first-line therapy. Patients with notable characteristics of aggressive disease, such as refractoriness to first-line treatment or rapid time to progression on first-line treatment, have a poor prognosis in the second-line setting [3-6]. Recent exploratory subgroup analyses have demonstrated the benefit of antiangiogenic therapy in combination with docetaxel for patients with rapidly progressing or refractory NSCLC $[4,7-10]$. In addition, the identification of predictive or prognostic markers that would enrich future clinical trial populations for patients who may respond better to antiangiogenic treatment may improve outcomes even further.

Ramucirumab in combination with docetaxel is approved by the US Food and Drug Administration, the European Medicines Agency, and Japan's Pharmaceuticals Medical Devices Agency in the second-line setting to treat patients with advanced NSCLC who progressed on or after platinum-based chemotherapy based on the results of the phase III REVEL study (ClinicalTrials.gov Identifier NCT01168973) [11,12]. Patients in the REVEL study treated with ramucirumab plus docetaxel had improved overall survival (OS) (10.5 vs. 9.1 months; hazard ratio [HR] 0.86 [95\% confidence interval (Cl) 0.75-0.98]; $P=0.023$ ), progression-free survival (PFS) (4.5 vs. 3.0 months; HR 0.76 [95\% Cl 0.68-0.86]; $P<0.001)$, and objective response rate (ORR) (23\% vs. $14 \%$; odds ratio [OR] 1.89 [95\% Cl 1.41-2.54]; $P<0.0001)$ compared with patients treated with docetaxel [11]. Consistent with a manageable toxicity profile, patient-reported symptoms and quality of life (QoL), as well as clinician-reported patient functioning measured by the Lung Cancer Symptom Scale (LCSS) and Eastern Cooperative Oncology Group performance status (ECOG PS), were similar between treatment 
arms [13]. Similar results were seen in exploratory subgroup analyses of patients from the REVEL study. These results demonstrated that patients refractory to first-line treatment (those with a best response of progressive disease [PD] to first-line therapy) and patients with rapidly progressing disease (those with a time to progression on first-line therapy within 9,12 , or 18 weeks or those who had $<9$ months between the start of first- and second-line therapy) had similar efficacy and safety outcomes to the intent-to-treat (ITT) population $[7,8,11]$.

Patients with NSCLC experience symptoms that commonly include dyspnea, cough, fatigue, anorexia, and pain, which affect the physical as well as functional aspects of a patient's QoL [14-16]. Symptom burden is significantly higher in patients with more advanced NSCLC [17] and in those receiving more advanced lines of treatment [18]. Thus, control of symptoms and maintenance of QoL for patients with advanced NSCLC are essential parts of the decision-making process regarding treatment options and provide crucial information for the assessment of disease, clinician-reported functional status, and treatment symptom burden as well as the effectiveness of treatment $[13,19]$.

The potential prognostic value of patient symptoms and function for survival in cancer clinical trials has been previously noted [20-23]. Specific to lung tumors, baseline patient-reported symptoms, as measured by the LCSS and the Average Symptom Burden Index (ASBI; average of the 6 symptom components of the LCSS) have demonstrated prognostic value for OS in post hoc analyses of both malignant mesothelioma and nonsquamous NSCLC $[24,25]$. Understanding the potential prognosis of patients can be important information when balancing the selection of new drug therapies based on risk, tolerability, and clinical benefit for any given patient. 
In this post hoc analysis of the randomized, controlled phase III REVEL study, we studied the association of baseline symptom burden with the efficacy of ramucirumab plus docetaxel. Our objectives were to (1) describe the patient population experiencing low symptom burden (LSB) and high symptom burden (HSB) per the LCSS ASBI, (2) evaluate the prognostic value of baseline ASBI in patients with advanced or metastatic NSCLC in the second-line setting, and (3) evaluate the efficacy of ramucirumab in the ASBI-defined subgroups.

\section{MATERIALS AND METHODS}

\subsection{Patients and Treatment}

The phase III REVEL study design has been published previously [11]. Patients included in this study were at least 18 years of age with histologically or cytologically confirmed squamous or nonsquamous stage IV NSCLC who had progressed during or after a single platinum-based chemotherapy regimen, with or without bevacizumab or maintenance therapy. At study entry, patients were required to have an ECOG PS of 0 or 1 . Patients were randomized $1: 1$ to receive intravenous docetaxel $75 \mathrm{mg} / \mathrm{m}^{2}$ plus intravenous ramucirumab $10 \mathrm{mg} / \mathrm{kg}$ or intravenous docetaxel $75 \mathrm{mg} / \mathrm{m}^{2}$ plus placebo on day 1 of a 21-day cycle until radiographically confirmed disease progression, unacceptable toxicity, withdrawal, or death.

\subsection{Assessments}

The timing and measurement of survival, progression, response rate, and LCSS-measured tumor-related symptoms have been described previously $[11,13,26]$. The LCSS patient scale is a reliable and valid lung cancer-specific instrument measuring patient-reported symptoms. The LCSS questionnaire consists of nine items, each scored with a 100-mm visual analog scale, used to 
evaluate six lung cancer symptoms (appetite loss, fatigue, cough, dyspnea, hemoptysis, and pain) and 3 global items assessing total symptomatic distress, activity status, and quality of life (symptom distress, activity level, and global QoL). Each item is scored from 0 (none) to 100 (worst). LCSS data were scored according to developer guidelines (http://www.lcss-ql.com/). The ASBI was calculated as the mean of the six symptom items, and the LCSS total score was calculated as the mean of all nine items. For a given assessment, the ASBI or the LCSS total scores were not calculated if there were one or more missing values. A higher score for ASBI or LCSS total score represented a higher level of symptoms. For this post-hoc analysis, symptom burden subgroups were predefined in our analysis plan based on previous literature [25] by the calculated baseline median ASBI as the LSB group (ASBI $\leq$ median) and the HSB group (ASBI > median).

For subsequent comparison with the symptom subgroups, refractory patients were defined as those with "PD as the best response to prior therapy," and patients with rapidly progressing disease were those with "time to progression on first-line therapy within 12 weeks" [7,8]. Several cut-points of time to progression on first-line therapy were previously assessed [7]. Cut-points in multiples of 3 weeks were identified to align with a typical cycle length in first-line therapy. Patients in the REVEL study with a time to progression on first-line therapy within 9,12 , and 18 weeks had similar efficacy and safety results [6,8]. The 12-week threshold also aligns with a typical first post-baseline scan and was chosen as the representative cut-point in the present analysis for patients with rapidly progressing disease.

\subsection{Statistical Methods}

Survival data were analyzed using the Kaplan-Meier method and Cox proportional hazards regression model stratified by randomization strata as previously reported [11]. We compared ORRs (percentage of patients with a complete response [CR] or 
partial response $[P R])$ and disease control rates (DCR; percentage of patients with $C R, P R$, or stable disease [SD]) in each treatment group using the Cochran-Mantel-Haenszel test. Logistic regression analysis was used to associate between the best tumor response (ORR, DCR) and ASBI. In the model, the binary objective response (CR/PR vs. SD/PD) was the dependent variable and the LCSS variable was the independent variable. The model was adjusted by pre-specified baseline characteristics: geographical region, ECOG PS, prior maintenance therapy, sex, smoking history, histology, best response to platinum-based chemotherapy, prior taxane treatment, prior bevacizumab, epidermal growth factor receptor status, age, race, and time since prior therapy [11]. Treatment effect within each subgroup was considered significant with a $P$ value of less than 0.05 ; the interaction effect between treatment and subgroup was considered significant with a $P$ value of less than 0.20 as previously described [25,27]. Overlap between the populations of REVEL patients with aggressive (refractory or rapidly progressing) disease and those with HSB were assessed using chi-square tests. Subgroups of patients from the REVEL study with refractory or rapidly progressing disease were previously described $[7,8]$.

\section{RESULTS}

\subsection{Patients}

At baseline, overall LCSS compliance was approximately $78 \%$ in both treatment arms, and 994 patients had ASBI values

[13]. Baseline ASBI scores were available for 493 (79\%) of 628 ramucirumab plus docetaxel patients and 501 (80\%) of 625 placebo plus docetaxel patients [13]. 
The median baseline ASBI score was 24.3 and the mean was 25.7 (Table 1). There were 497 patients in each of the LSB and HSB categories, defined as having values below or above the ASBI median of 24.3, respectively. Other LCSS items below and above the ASBI median are characterized in Table 1.

Baseline patient and disease characteristics for patients by ASBI subgroup (LSB and HSB) and by treatment arm are shown in Table 2. Characteristics were generally well balanced between treatment arms and among subgroups with some notable differences. A higher percentage of the total HSB patients versus LSB patients had an ECOG PS of 1 (77\% vs. $57 \%)$, PD as best response to first-line therapy ( $33 \%$ vs. $25 \%$ ), and time since start of prior therapy $<9$ months (65\% vs. $57 \%$ ) (Table 2 ), which is consistent with more aggressive disease. These were slightly different from what was observed previously from patients in the ITT population treated in the ramucirumab arm versus the placebo arm, respectively: ECOG PS of 1 was $67 \%$ versus 68\%; PD as best response to platinum-based chemotherapy was $28 \%$ versus $29 \%$; and time since prior therapy $<9$ months was $64 \%$ versus $60 \%$. The remaining baseline patient and disease characteristics in the LSB and HSB subgroups were similar to those in the ITT population as previously reported [11].

The occurrence of patients with baseline HSB overlapped and was statistically associated with the occurrence of patients with refractory disease $(P=0.008)$ and moderately associated with the occurrence of REVEL patients with rapidly progressing disease $(P=0.059)$ (Table 3 and Supplementary Fig. 1). Approximately $57 \%$ of patients refractory to first-line therapy reported baseline HSB ( $n=164$ of 290 refractory patients) and 43\% reported baseline LSB ( $n=126$ of 290 refractory patients). Similarly, 57\% of patients with rapidly progressing disease that progressed within 12 weeks on first-line therapy reported baseline HSB ( $n=92$ of 162 patients with rapidly progressing disease), and 43\% reported baseline LSB ( $n=70$ of 162 patients). 


\subsection{Baseline ASBI Association With OS}

When controlling for the known prognostic factors as detailed in section 2.3, patients with baseline LSB across both treatment arms had improved OS when compared with patients with HSB (median OS: LSB 12.35 vs. HSB 6.67 months; HR 0.575 [95\% Cl 0.491-0.672]; $P<0.0001$ ) (Fig. 1A). Fig. 2A and 2B show the Kaplan-Meier curves for OS by treatment arm within ASBI subgroups. In the LSB subgroup, median OS was similar between treatment arms (12.25 vs. 12.62 months; HR 0.88 [95\% $\mathrm{Cl} 0.701-1.112]$; $P=0.9510$ ) (Fig. 2A). In the HSB subgroup, the addition of ramucirumab to docetaxel significantly improved OS versus docetaxel alone (7.39 vs. 5.95 months; HR 0.749 [95\% Cl 0.610-0.920]; P=0.0308) (Fig. 2B). As shown in Fig. 1A, a significant interaction effect as defined in the methods section $2.3(P<0.20)$ was seen between treatments and ASBI subgroups for OS $(P$-value for interaction=0.123). The significant interaction is also shown in Fig. 2A and 2B, in which the OS in the LSB subgroup was similar between the ramucirumab and placebo arm whereas the OS in the HSB subgroup was significantly longer in the ramucirumab arm when compared with the placebo arm.

\subsection{Baseline ASBI Association With PFS}

Across treatment arms, patients with baseline LSB had improved PFS when compared with patients with HSB (median PFS: LSB 4.44 months vs. HSB 2.89 months; HR 0.748 [95\% Cl 0.652-0.860]; $P<0.0001$ ) (Fig. 1B). Fig. 2C and 2D show the Kaplan-

Meier curves for PFS by treatment arm within ASBI subgroups. The addition of ramucirumab to docetaxel significantly improved PFS versus docetaxel alone for patients with LSB (median PFS: 5.39 vs. 4.27 months; HR 0.672 [95\% Cl 0.552-0.818]; P=0.0148) (Fig. 
2C) and HSB (median PFS: 4.01 vs. 2.63 months; HR 0.749 [95\% Cl 0.619-0.907]; P=0.0202) (Fig. 2D). However, no significant interaction effect was observed between ramucirumab treatment and ASBI subgroups for PFS ( $P=0.973)$ (Fig. 1B).

\subsection{Association of ASBI With Response}

Across treatment arms, patients with LSB had significantly higher ORR and DCR than those with HSB (ORR 23\% vs. 14\%; $P=0.0003$; DCR $65 \%$ vs. 52\%; $P<0.0001)$. In patients with baseline LSB, ORR and DCR were significantly higher in the ramucirumab plus docetaxel group versus the docetaxel group (ORR 29\% vs. 17\%; $P=0.0021$; DCR $69 \%$ vs. $60 \%$; $P=0.0366$ ) (Table 4). Similarly,

in patients with baseline HSB, ORR and DCR were significantly higher in the ramucirumab plus docetaxel group versus the docetaxel group (ORR 18\% vs. 11\%; $P=0.0458$; DCR 58\% vs. 47\%; $P=0.0068$ ) (Table 4). Baseline ASBI was associated with tumor ORR when evaluated in a logistic regression analysis adjusting for treatment groups (OR, 0.982 [95\% $\mathrm{Cl} 0.971-0.993] ; P=0.0018)$ and remained statistically significant after multivariable analysis controlling for other prognostic factors (OR 0.988 [95\% $\mathrm{Cl} 0.976-0.999] ; P=0.0347)$.

\subsection{Safety by ASBI Subgroup}

The incidence of adverse events was similar between the ASBI subgroup treatment arms and among the pooled ASBI subgroups, with a few exceptions. In LSB versus HSB patients, a lower incidence of treatment-emergent adverse events leading to death (3.4\% vs. $7.5 \%)$ and treatment-emergent serious adverse events (37.3\% vs. $49.7 \%)$ was observed (Supplementary Table 1$)$.

\section{DISCUSSION}


Regardless of treatment, patients from the REVEL study with patient-reported baseline LSB had significantly longer OS and PFS and higher ORR than patients who reported baseline HSB, reinforcing findings from previous research that symptom burden may be a useful prognostic factor for patients with advanced NSCLC. More patients with baseline HSB versus LSB were refractory to first-line chemotherapy or had a time to progression within 12 weeks on first-line treatment- - known hallmarks of tumor

aggressiveness. In fact, there was a significant association between the occurrence of baseline HSB and the occurrence of refractory or rapidly progressing disease in REVEL patients. The occurrence of REVEL patients with refractory disease was also significantly associated with that of patients with rapidly progressing disease $(P<0.001)$. The median PFS and OS results of patients who reported HSB at baseline were also consistent with other exploratory REVEL subgroups with aggressive disease (Supplementary Table 2)

$[7,8,11]$. All of this reflects $\mathrm{ASBI}$ as a probable symptomatic manifestation of these clinical prognostic indicators of aggressive disease. These results suggest that patients with HSB or aggressive disease benefit from treatment with ramucirumab plus docetaxel versus docetaxel alone with an acceptable toxicity profile and overall QoL functioning.

The prognostic impact of the HSB description and the overlap with other descriptions for patients with aggressive disease suggest internal consistency of those populations. The preserved efficacy of OS, PFS, and ORR associated with ramucirumab plus docetaxel in patients with baseline HSB suggests that the treatment effect is likely to be robust and that symptom burden is an important consideration when selecting second-line treatment. The higher rates of serious adverse events associated with death seen in patients with HSB suggest a need for close monitoring of patients and assertive use of supportive care.

As with any post hoc exploratory analysis, there are limitations that will impact both generalizability and interpretation. First, these analyses were not powered to detect differences between the treatment arms nor were they powered to detect potential effect 
differences between LSB and HSB subgroups. Additionally, a baseline LCSS compliance of less than $80 \%$ may indicate that these analyses are not representative of the entire REVEL patient population as missing data may not be missing at random. Another limitation of this study was that the median cut-point for data analysis was derived based on the median ASBI score and not anchored to a more clinically relevant empirical determination. However, previous research has determined symptom burden defined as low and high by an ASBI score of 25 aligns with the "mild" category of the LCSS observer scale [25]. The observer scale contains the 6 ASBI symptoms and rates them using a 5-point categorical scale (none, mild, moderate, marked, and severe) [25]. In this study, the near-perfect agreement of the calculated statistical median ASBI score of 24.3 with the previously cited cut-point of 25 suggests a level of alignment for distinguishing a mild category of the LCSS observer scale.

Other studies have reported on the prognostic significance of the LCSS ASBI and patient-reported outcomes in general [2025]. From a meta-analysis of 30 randomized controlled trials of 11 different tumor types from the European Organization for Research and Treatment of Cancer, select health-related QoL parameters of physical functioning, appetite loss, and pain provided significant prognostic value in addition to sociodemographic and clinical variables [19]. Prognostic outcomes specific to the LCSS have been reported in a phase III trial of malignant pleural mesothelioma. Again, patient-reported symptom burden was dichotomized by LSB and HSB as measured by ASBI. In the multivariable analysis adjusted for demographic/clinical variables, the ASBI was prognostic because patients with LSB $(\mathrm{ASBI}<25)$ had longer OS than those with HSB (ASBI $\geq 25)[24]$.

In patients with nonsquamous advanced NSCLC, Obasaju et al. used this same approach to demonstrate how baseline ASBI and ECOG PS may better inform clinicians to identify the appropriate patients for using maintenance pemetrexed [25]. Whereas patients with LSB $(\mathrm{ASBI}<25)$ had improved PFS and OS after treatment with maintenance pemetrexed, patients with HSB (ASBI 
225) demonstrated greater difficulty in receiving benefit and only had a small improvement in PFS and no improvement in OS [25].

Obasaju et al. also substantiated through multivariable analyses that ECOG PS and ASBI were independent predictors of this differential response [25]. In our study, patients treated with ramucirumab-docetaxel with baseline HSB had significant OS and PFS benefits, and patients treated with ramucirumab-docetaxel with baseline LSB had a significant PFS benefit. Median OS in patients with LSB was just over 12 months in both treatment arms, which is higher than that observed for the REVEL ITT population, but not significantly different between treatment arms in this analysis. However, these results should be interpreted with caution due to the exploratory nature of these analyses. Determining the prognostic value of clinician-reported performance status was not an objective in this study; however, similar to the populations analyzed by Obasaju et al., REVEL patients with HSB were more likely to have ECOG PS 1 when compared with patients with baseline LSB (Table 2; 77\% vs 57\%). Thus, it is possible that both baseline ASBI lung cancer symptom data and clinician-reported performance status may be used as complementary tools, in addition to efficacy and safety data, to better inform clinical decision making for patients with advanced NSCLC [28]. The consistency of the literature regarding the prognostic value of symptoms at the common cut-point suggests a level of reliability and robustness from these REVEL post hoc ASBI-defined subgroups. The relative similarity of the PFS and OS HRs with those determined from the aggressive disease subgroups previously reported from the REVEL ITT population suggests a consistency of the effect of ramucirumab plus docetaxel on aggressive disease subgroups [7,8,11].

\section{CONCLUSIONS}

In this post hoc analysis of the phase III REVEL study, results indicate that ASBI for advanced NSCLC may be a useful prognostic factor. Additionally, treatment with ramucirumab plus docetaxel for patients with HSB was associated with improved 
outcomes (OS, PFS, and ORR) compared with placebo plus docetaxel. These results were internally consistent with those reported for patient subgroups with refractory and rapidly progressing disease. Although this analysis was exploratory, the preservation of improved PFS and OS in the HSB cohort suggests that ramucirumab plus docetaxel maintains an incremental efficacy over docetaxel alone in patients with aggressive disease as defined by symptoms or other clinical characteristics. 


\section{ACKNOWLEDGEMENTS}

We thank the patients, their families, the study sites, and the study personnel who participated in this clinical trial. Eli Lilly and

Company contracted with Syneos Health for writing support provided by Andrea D. Humphries, PhD, and editing support provided by Sarah Becker-Marrero, ELS.

\section{FUNDING}

This work was supported by Eli Lilly and Company.

\section{Role of Funding Source}

The study sponsor provided study drug and collaborated with investigators on study design, data collection, analysis, and interpretation, and preparation of this report. All drafts were written in collaboration with the sponsor and coauthors. The principal investigators had full access to all data, and all authors had final responsibility for the decision to submit for publication. 


\section{References}

[1] American Cancer Society. Cancer Facts \& Figures 2018. https://www.cancer.org/content/dam/cancer-org/research/cancerfacts-and-statistics/annual-cancer-facts-and-figures/2018/cancer-facts-and-figures-2018.pdf, 2018 (accessed 05 February 2018).

[2] A. Carrato, A. Vergnenègre, M. Thomas, K. McBride, J. Medina, G. Cruciani, Clinical management patterns and treatment outcomes in patients with non-small cell lung cancer (NSCLC) across Europe: EPICLIN-Lung study, Curr. Med. Res. Opin. 30 (2014) 447-461.

[3] M. Cobo, V. Gutiérrez, R. Villatoro, J.M. Trigo, I. Ramos, O. López, M. Ruiz, A. Godoy, I. López, M. Arroyo, Spotlight on ramucirumab in the treatment of nonsmall cell lung cancer: design, development, and clinical activity, Lung Cancer (Auckl) 8 (2017) 57-66.

[4] B. Gaschler-Markefski, P. Sikken, J.V. Heymach, M. Gottfried, A. Mellemgaard, S. Novello, C.N. Gann, J. Barrueco, M. Reck, N.H. Hanna, R. Kaiser, Time since start of first-line therapy as a predictive clinical marker for nintedanib in patients with previously treated non-small cell lung cancer, ESMO Open 2 (2017) e000102.

[5] D. Heigener, M. Gottfried, J. Bennouna, I. Bondarenko, J-Y. Douillard, M. Krzakowski, A. Mellemgaard, S. Novello, S. Orlov, Y.J. Summers, J. von Pawel, J. Hocke, R. Kaiser, M. Reck, Efficacy and safety of nintedanib (NIN)/docetaxel (DOC) in patients with lung adenocarcinomas: Further analyses from the LUME-Lung 1 study, Presented at the ESMO 2016 Congress, Copenhagen, Denmark, October 7-11, 2016. Ann. Oncol. 27 (Suppl 6) (2016), (abstract 1267P).

[6] M. Reck, M.C. Garassino, M. Imbimbo, F.A. Shepherd, M.A. Socinski, J.Y. Shih, A. Tsao, P. Lee, K.B. Winfree, A. Sashegyi, R. Cheng, R. Varea, B. Levy, E. Garon, Antiangiogenic therapy for patients with aggressive or refractory advanced non-small cell lung cancer in the second-line setting, Lung Cancer 120 (2018) 62-69.

[7] M. Reck, L. Paz-Ares, P. Bidoli, F. Cappuzzo, S. Dakhil, D. Moro-Sibilot, H. Borghaei, M. Johnson, R. Jotte, N.A. Pennell, F.A. Shepherd, A. Tsao, M. Thomas, G.C. Carter, F. Chan-Diehl, E. Alexandris, P. Lee, A. Zimmermann, A. Sashegyi, M. Pérol, Outcomes in patients with aggressive or refractory disease from REVEL: a randomized phase III study of docetaxel with ramucirumab or placebo for second-line treatment of stage IV non-small-cell lung cancer, Lung Cancer 112 (2017) 181187.

[8] M. Reck, F.A. Shepherd, M. Pérol, F. Cappuzzo, J. Shih, K. Park, K. Winfree, E. Alexandris, P. Lee, A. Sashegyi, E. Garon, Effect of $2 \mathrm{~L}$ ramucirumab after rapid time to progression on $1 \mathrm{~L}$ therapy: subgroup analysis of REVEL in advanced NSCLC, 
Presented at the IASLC 18th World Conference on Lung Cancer, Yokohama, Japan, October 15-18, 2017. J. Thorac. Oncol. 12 (11 Suppl 2) (2017) S1808-S1809, (abstract MA 03.06).

[9] R. Kaiser, J. Barrueco, M. Reck, Identification of a clinical biomarker for 2nd line combination with nintedanib in adenocarcinoma non-small cell lung cancer (NSCLC) patients in two phase III trials, Eur. J. Cancer 49 (2013), (abstract 3479).

[10] M. Reck, R. Kaiser, A. Mellemgaard, J.Y. Douillard, S. Orlov, M. Krzakowski, J. von Pawel, M. Gottfried, I. Bondarenko, M. Liao, C.N. Gann, J. Barrueco, B. Gaschler-Markefski, S. Novello; LUME-Lung 1 Study Group, Docetaxel plus nintedanib versus docetaxel plus placebo in patients with previously treated non-small-cell lung cancer (LUME-Lung 1): a phase 3, double-blind, randomised controlled trial, Lancet Oncol. 15 (2014) 143-155.

[11] E.B. Garon, T.E. Ciuleanu, O. Arrieta, K. Prabhash, K.N. Syrigos, T. Goksel, K. Park, V. Gorbunova, R.D. Kowalyszyn, J. Pikiel, G. Czyzewicz, S.V. Orlov, C.R. Lewanski, M. Thomas, P. Bidoli, S. Dakhil, S. Gans, J.H. Kim, A. Grigorescu, N. Karaseva, M. Reck, F. Cappuzzo, E. Alexandris, A. Sashegyi, S. Yurasov, M. Pérol, Ramucirumab plus docetaxel versus placebo plus docetaxel for second-line treatment of stage IV non-small-cell lung cancer after disease progression on platinum-based therapy (REVEL): a multicentre, double-blind, randomised phase 3 trial, Lancet 384 (2014) 665-673.

[12] E. Larkins, B. Scepura, G.M. Blumenthal, E. Bloomquist, S. Tang, M. Biable, P. Kluetz, P. Keegan, R. Pazdur, U.S. Food and Drug Administration approval summary: Ramucirumab for the treatment of metastatic non-small cell lung cancer following disease progression on or after platinum-based chemotherapy, Oncologist 20 (2015) 1320-1325.

[13] M. Pérol, T.E. Ciuleanu, O. Arrieta, K. Prabhash, K.N. Syrigos, T. Goksel, K. Park, R.D. Kowalyszyn, J. Pikiel, C.R. Lewanski, M. Thomas, S. Dakhil, J.H. Kim, N. Karaseva, S. Yurasov, A. Zimmermann, P. Lee, G.C. Carter, M. Reck, F. Cappuzzo, E.B. Garon, Quality of life results from the phase 3 REVEL randomized clinical trial of ramucirumab-plus-docetaxel versus placebo-plus-docetaxel in advanced/metastatic non-small cell lung cancer patients with progression after platinum-based chemotherapy, Lung Cancer 93 (2016) 95-103.

[14] A. Bottomley, F. Efficace, R. Thomas, V. Vanvoorden, S.H. Ahmedzai, Health-related quality of life in non-small-cell lung cancer: methodologic issues in randomized controlled trials, J. Clin. Oncol. 21 (2003) 2982-2992.

[15] M.E. Cooley, Symptoms in adults with lung cancer. A systematic research review, J. Pain Symptom Manage. 19 (2000) 137153.

[16] C. Tishelman, L.F. Degner, A. Rudman, K. Bertilsson, R. Bond, E. Broberger, E. Doukkali, H. Levealahti, Symptoms in patients with lung carcinoma: distinguishing distress from intensity, Cancer 104 (2005) 2013-2021. 
[17] S. Iyer, A. Roughley, A. Rider, G. Taylor-Stokes, The symptom burden of non-small cell lung cancer in the USA: a real-world cross-sectional study, Support. Care Cancer 22 (2014) 181-187.

[18] S. Iyer, G. Taylor-Stokes, A. Roughley, Symptom burden and quality of life in advanced non-small cell lung cancer patients in France and Germany, Lung Cancer 81 (2013) 288-293.

[19] C. Quinten, C. Coens, M. Mauer, S. Comte, M.A. Sprangers, C. Cleeland, D. Osoba, K. Bjordal, A. Bottomley; EORTC Clinical Groups, Baseline quality of life as a prognostic indicator of survival: a meta-analysis of individual patient data from EORTC clinical trials, Lancet Oncol. 10 (2009) 865-871.

[20] C.C. Gotay, C.T. Kawamoto, A. Bottomley, F. Efficace, The prognostic significance of patient-reported outcomes in cancer clinical trials, J. Clin. Oncol. 26 (2008) 1355-1363.

[21] C.A. Hauser, M.R. Stockler, M.H. Tattersall, Prognostic factors in patients with recently diagnosed incurable cancer: a systematic review, Support. Care Cancer 14 (2006) 999-1011.

[22] D. Osoba, Lessons learned from measuring health-related quality of life in oncology, J. Clin. Oncol. 12 (1994) 608-616.

[23] M.A. Sprangers, Quality-of-life assessment in oncology. Achievements and challenges, Acta Oncol. 41 (2002) $229-237$.

[24] P. Wang, L. Bowman, W. Shen, K.B. Winfree, P. Peterson, W.J. John, The Lung Cancer Symptom Scale (LCSS) as a prognostic indicator of overall survival in malignant pleural mesothelioma (MPM) patients: Post hoc analysis of a phase III study, J. Clin. Oncol. 30 (15 Suppl) (2012), (abstract 7075).

[25] C. Obasaju, L. Bowman, P. Wang, W. Shen, K.B. Winfree, E.N. Smyth, M.E. Boye, W. John, T. Brodowicz, C.P. Belani, Identifying the target NSCLC patient for maintenance therapy: an analysis from a placebo-controlled, phase III trial of maintenance pemetrexed (H3E-MC-JMEN), Ann. Oncol. 24 (2013) 1534-1542.

[26] P.J. Hollen, R.J. Gralla, M.G. Kris, C. Cox C, Quality of life during clinical trials: conceptual model for the Lung Cancer Symptom Scale (LCSS), Support. Care Cancer 2 (1994) 213-222.

[27] S. Selvin, B. Abrams, Statistical Analysis of Epidemiologic Data, New York, Oxford University Press, 1996, pp. $213-214$.

[28] P.G. Kluetz, A. Slagle, E.J. Papadopoulos, L.L. Johnson, M. Donoghue, V.E. Kwitkowski, W.H. Chen, R. Sridhara, A.T. Farrell, P. Keegan, G. Kim, R. Pazdur, Focusing on core patient-reported outcomes in cancer clinical trials: symptomatic adverse events, physical function, and disease-related symptoms, Clin. Cancer Res. 22 (2016) 1553-1558. 

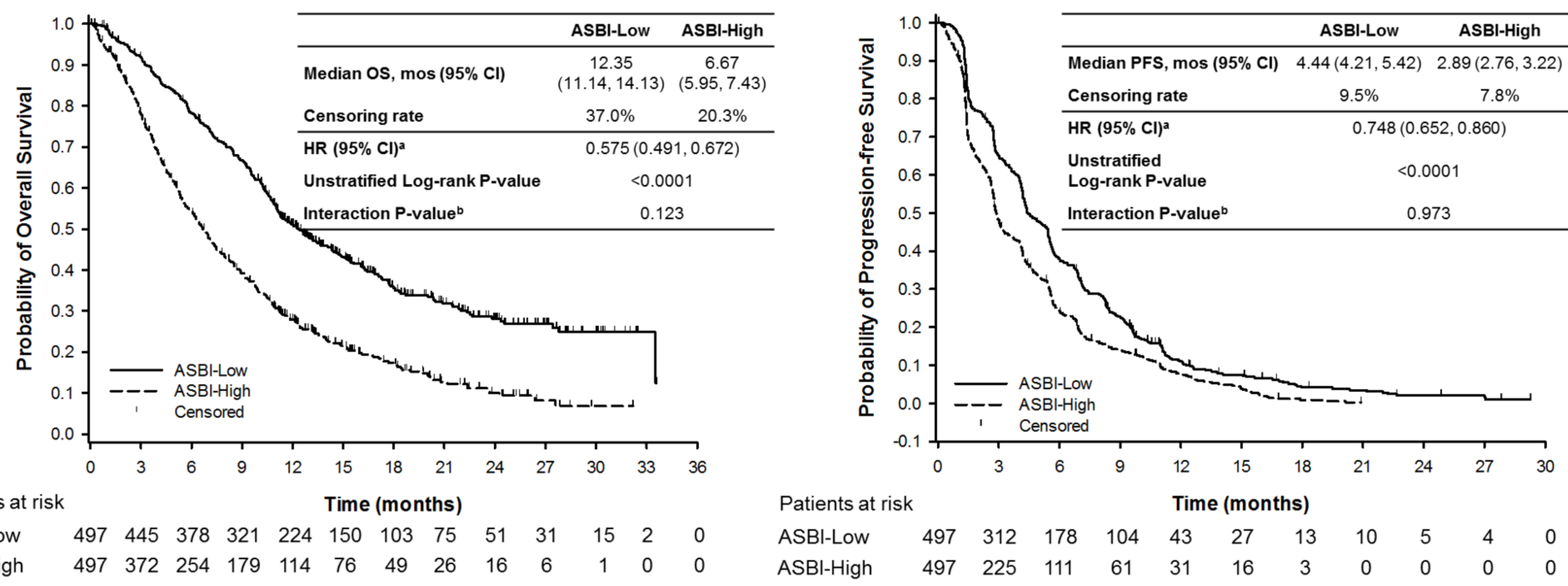

Patients at risk

Time (months)

Patients at risk

ASBI-Low

$\begin{array}{lllllll}497 & 225 & 111 & 61 & 31 & 16 & 3\end{array}$

ASBI-High

ASBI-High

$\begin{array}{ccccccccccccc}497 & 445 & 378 & 321 & 224 & 150 & 103 & 75 & 51 & 31 & 15 & 2 & 0 \\ 497 & 372 & 254 & 179 & 114 & 76 & 49 & 26 & 16 & 6 & 1 & 0 & 0\end{array}$

RUDI-TII 


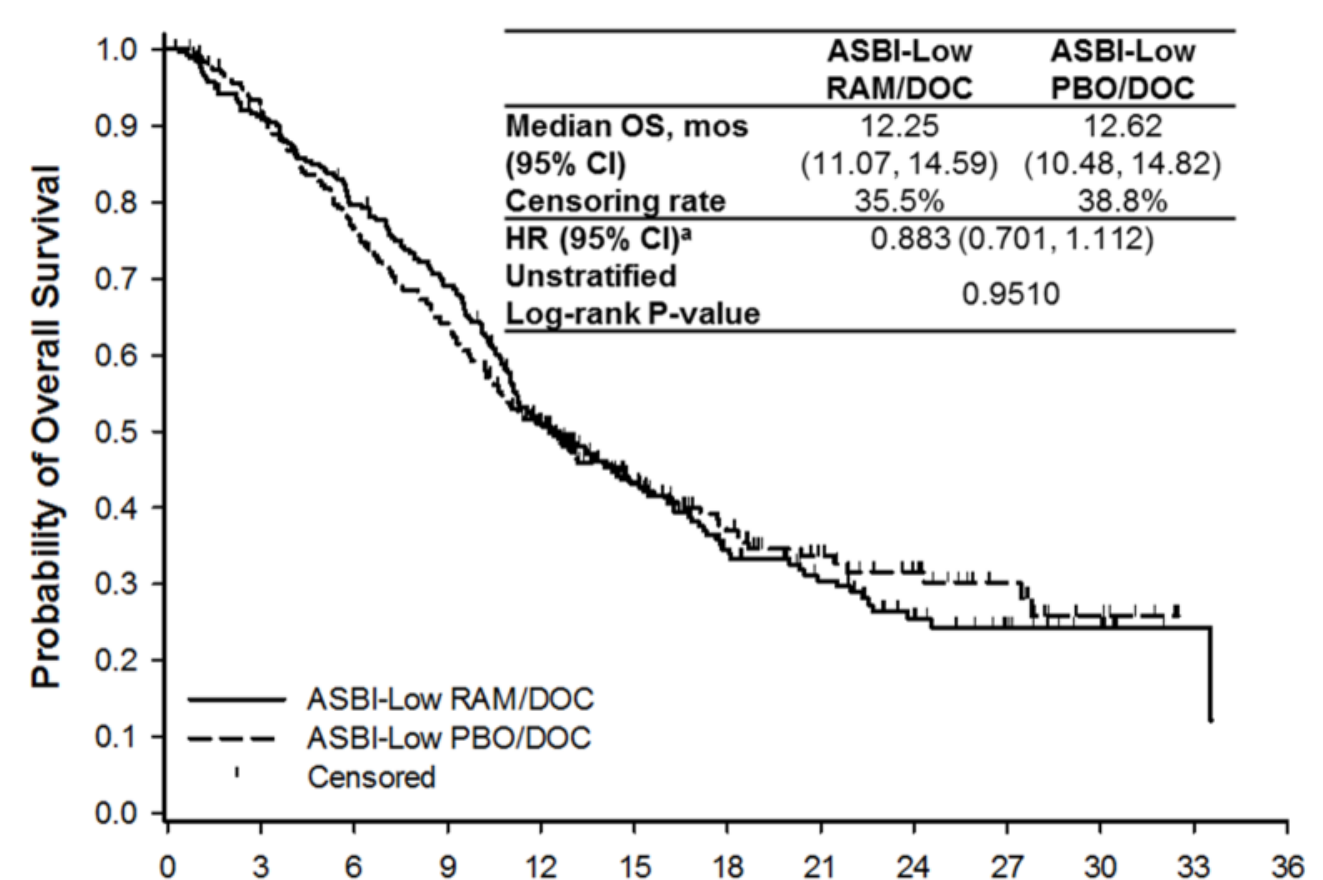

Patients at risk

Time (months)

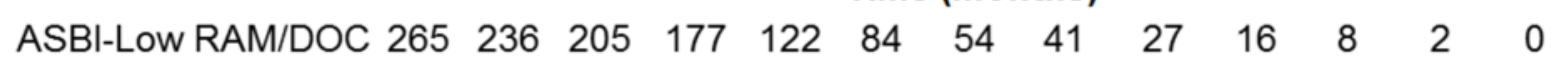

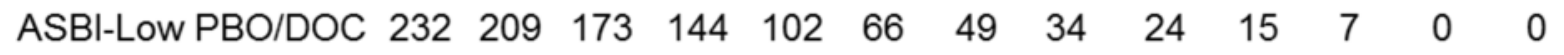

\section{B}

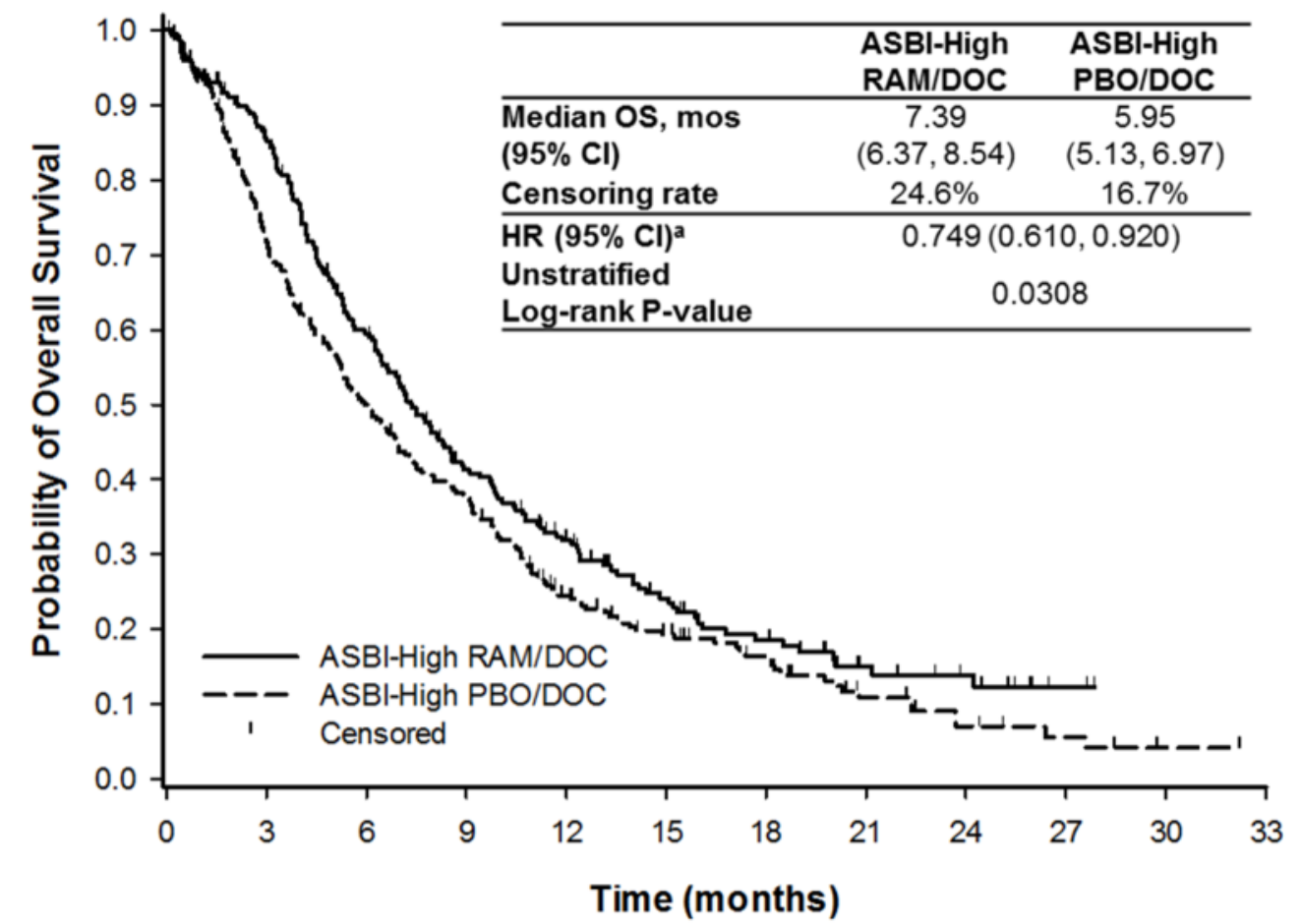

Patients at risk

Time (months)

$\begin{array}{lllllllllllll}\text { ASBI-High RAM/DOC } & 228 & 186 & 126 & 84 & 59 & 38 & 24 & 13 & 9 & 2 & 0 & 0\end{array}$

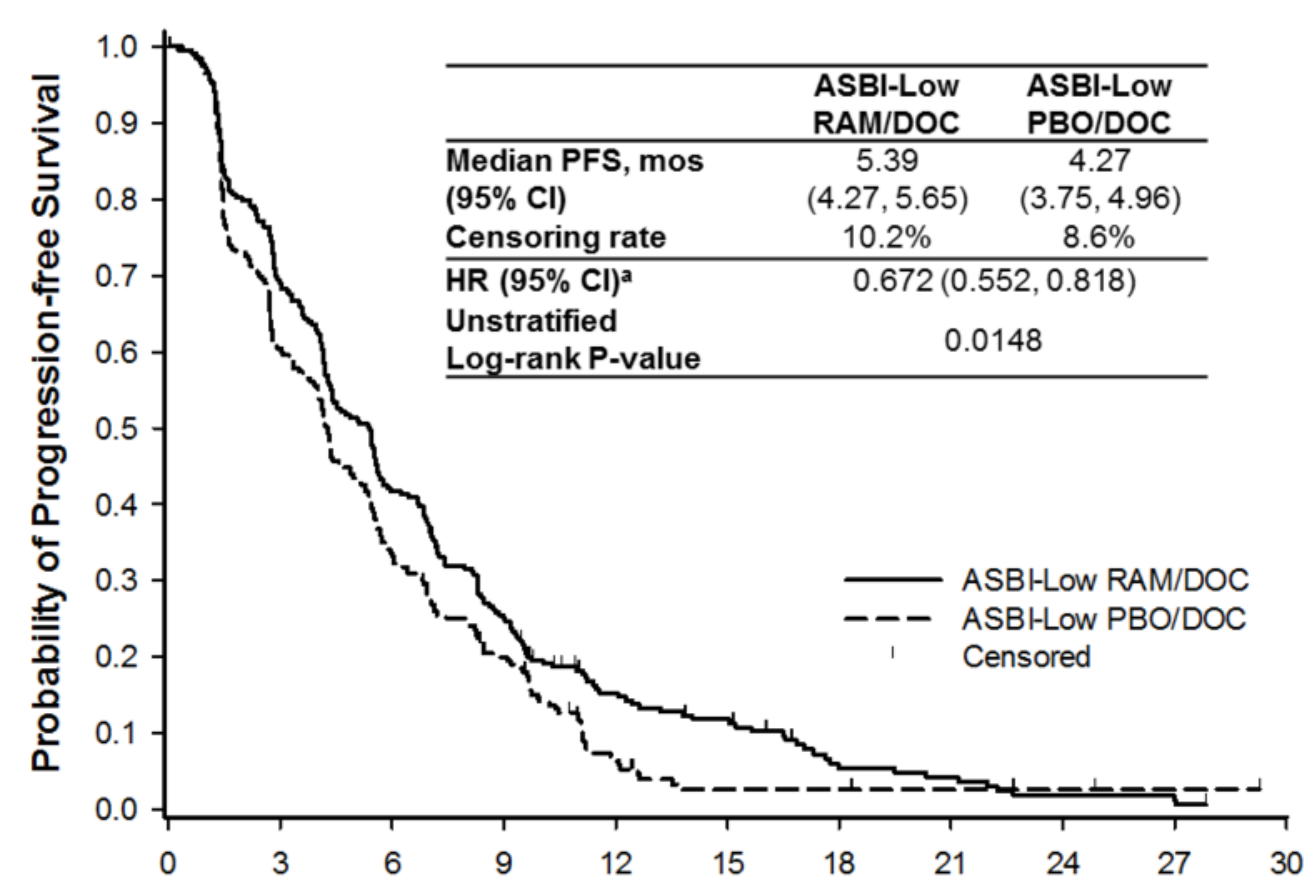

Patients at risk

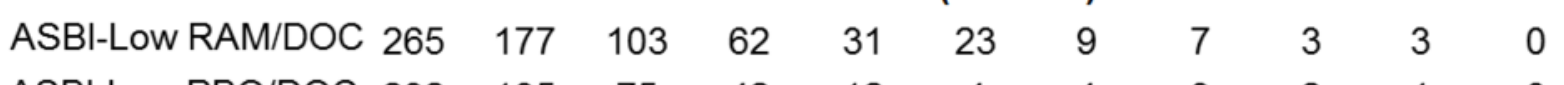

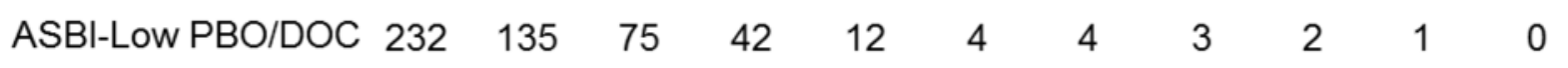

D

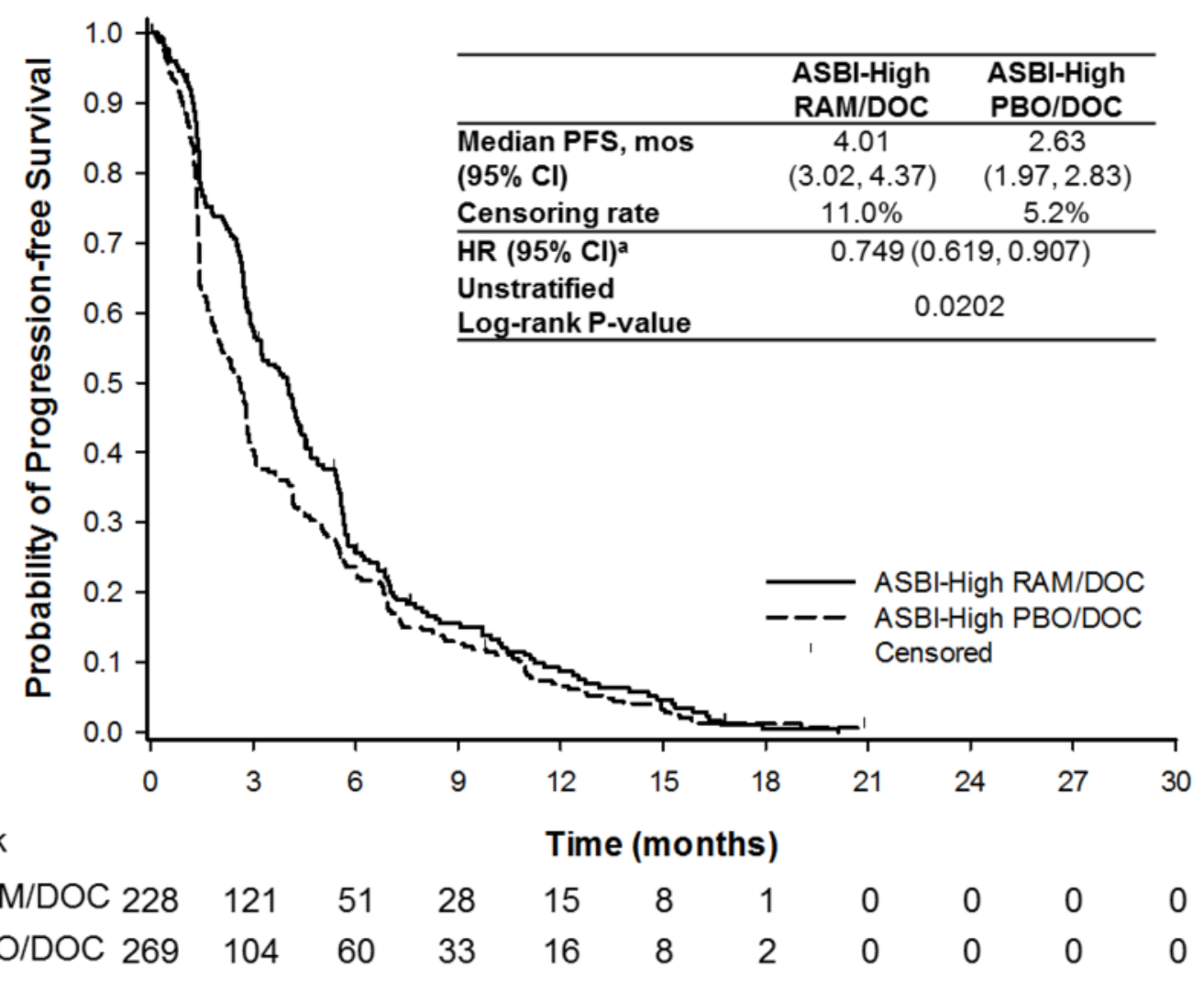


Table 1. Baseline LCSS Score Summary

\begin{tabular}{|c|c|c|c|c|}
\hline LCSS Item & Mean (SD) & Median & $\begin{array}{c}\text { Patients with } \\
\text { LCSS } \leq \text { median, } n\end{array}$ & $\begin{array}{c}\text { Patients with LCSS } \\
>\text { median, } n\end{array}$ \\
\hline \multicolumn{5}{|c|}{ Symptom scales } \\
\hline $\begin{array}{l}\text { Loss of } \\
\text { appetite }\end{array}$ & $28.5(26.5)$ & 20.5 & 512 & 512 \\
\hline Fatigue & $39.0(26.6)$ & 40.0 & 517 & 511 \\
\hline Cough & $28.6(27.7)$ & 20.0 & 523 & 507 \\
\hline Dyspnea & $29.7(28.0)$ & 22.0 & 525 & 504 \\
\hline Hemoptysis & $2.6(8.3)$ & 0.0 & 652 & 380 \\
\hline Pain & $25.8(28.2)$ & 14.0 & 523 & 510 \\
\hline \multicolumn{5}{|l|}{ Global scales } \\
\hline $\begin{array}{l}\text { Symptom } \\
\text { distress }\end{array}$ & $29.6(27.5)$ & 22.0 & 518 & 510 \\
\hline Activity level & $35.5(27.7)$ & 31.0 & 520 & 507 \\
\hline Global QoL & $36.6(25.6)$ & 34.0 & 512 & 504 \\
\hline $\mathrm{ASB}^{\mathrm{a}}$ & $25.7(16.3)$ & 24.3 & 497 & 497 \\
\hline $\begin{array}{l}\text { LCSS total } \\
\text { score }^{\mathrm{b}}\end{array}$ & $28.5(17.4)$ & 26.9 & 488 & 487 \\
\hline
\end{tabular}

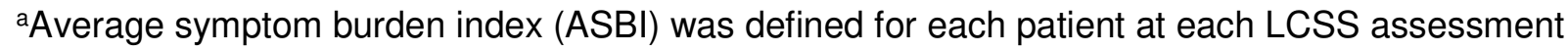
as the mean of all six symptom-specific items. For a given assessment, if any of the six symptom-specific questions was not completed, the ASBI was not calculated. A high ASBI score represents a high level of symptoms/problems.

${ }^{\mathrm{b}}$ The LCSS total score was defined as the mean of all nine items. For a given assessment, if any of the nine items was not completed, the total score was not calculated. A high total score represents a high level of symptoms/problems. 
Table 2. Baseline Patient Characteristics in REVEL ITT Population by ASBI Subgroup

\begin{tabular}{|c|c|c|c|c|c|c|}
\hline \multirow[b]{2}{*}{$\begin{array}{l}\text { Patient } \\
\text { Characteristics, n (\%) }\end{array}$} & \multicolumn{3}{|c|}{ LSB } & \multicolumn{3}{|c|}{ HSB } \\
\hline & $\begin{array}{c}\text { RAM } \\
(n=265)\end{array}$ & $\begin{array}{c}\text { PBO } \\
(n=232)\end{array}$ & $\begin{array}{c}\text { Total } \\
(\mathrm{N}=497)\end{array}$ & $\begin{array}{c}\text { RAM } \\
(n=228)\end{array}$ & $\begin{array}{c}\text { PBO } \\
(n=269)\end{array}$ & $\begin{array}{c}\text { Total } \\
(\mathrm{N}=497)\end{array}$ \\
\hline \multicolumn{7}{|l|}{ Age } \\
\hline$<65$ years & $175(66 \%)$ & $148(64 \%)$ & $323(65 \%)$ & $137(60 \%)$ & $188(70 \%)$ & $325(65 \%)$ \\
\hline$\geq 65$ years & $90(34 \%)$ & $84(36 \%)$ & $174(35 \%)$ & $91(40 \%)$ & $81(30 \%)$ & $172(35 \%)$ \\
\hline Male & $168(63 \%)$ & 147 (63\%) & $315(63 \%)$ & $157(69 \%)$ & $182(68 \%)$ & $339(68 \%)$ \\
\hline \multicolumn{7}{|l|}{ Race (self-reported) } \\
\hline White & $219(83 \%)$ & $178(77 \%)$ & 397 (80\%) & $192(84 \%)$ & 226 (84\%) & 418 (84\%) \\
\hline Asian & $34(13 \%)$ & $36(16 \%)$ & 70 (14\%) & $25(11 \%)$ & $34(13 \%)$ & $59(12 \%)$ \\
\hline Black & $8(3 \%)$ & $7(3 \%)$ & $15(3 \%)$ & $7(3 \%)$ & $7(3 \%)$ & $14(3 \%)$ \\
\hline Other & $4(2 \%)$ & $11(5 \%)$ & $15(3 \%)$ & $3(1 \%)$ & $2(1 \%)$ & $5(1 \%)$ \\
\hline \multicolumn{7}{|l|}{ ECOG PS } \\
\hline 0 & $117(44 \%)$ & $99(43 \%)$ & $216(43 \%)$ & $47(21 \%)$ & $64(24 \%)$ & $111(22 \%)$ \\
\hline 1 & $148(56 \%)$ & $133(57 \%)$ & $281(57 \%)$ & $181(79 \%)$ & 204 (76\%) & $385(77 \%)$ \\
\hline Measurable disease & $258(97 \%)$ & $225(97 \%)$ & $483(97 \%)$ & $216(95 \%)$ & 257 (96\%) & 473 (95\%) \\
\hline
\end{tabular}




\begin{tabular}{|c|c|c|c|c|c|c|}
\hline Ever & $214(81 \%)$ & $181(78 \%)$ & $395(79 \%)$ & $194(85 \%)$ & 207 (77\%) & $401(81 \%)$ \\
\hline Never & $51(19 \%)$ & $51(22 \%)$ & $102(21 \%)$ & $34(15 \%)$ & $61(23 \%)$ & 95 (19\%) \\
\hline \multicolumn{7}{|l|}{ Histology } \\
\hline Nonsquamous & $201(76 \%)$ & $168(72 \%)$ & $369(74 \%)$ & $169(74 \%)$ & $195(72 \%)$ & $364(73 \%)$ \\
\hline Squamous & $63(24 \%)$ & $59(25 \%)$ & $122(25 \%)$ & 57 (25\%) & $73(27 \%)$ & $130(26 \%)$ \\
\hline Unknown & $1(0 \%)$ & $5(2 \%)$ & $6(1 \%)$ & $2(1 \%)$ & $1(0 \%)$ & $3(1 \%)$ \\
\hline EGFR wild type & $90(34 \%)$ & $72(31 \%)$ & $162(33 \%)$ & $69(30 \%)$ & 75 (28\%) & $144(29 \%)$ \\
\hline $\begin{array}{l}\text { Best response to } \\
\text { platinum-based } \\
\text { chemotherapy }\end{array}$ & & & & & & \\
\hline $\mathrm{CR}, \mathrm{PR}$, or SD & $180(68 \%)$ & $162(70 \%)$ & $342(69 \%)$ & $144(63 \%)$ & $171(64 \%)$ & $315(63 \%)$ \\
\hline PD & $69(26 \%)$ & $57(25 \%)$ & $126(25 \%)$ & 74 (32\%) & $90(33 \%)$ & $164(33 \%)$ \\
\hline Missing & $16(6 \%)$ & $13(6 \%)$ & $29(6 \%)$ & $10(4 \%)$ & $8(3 \%)$ & $18(4 \%)$ \\
\hline $\begin{array}{l}\text { Previous maintenance } \\
\text { treatment }\end{array}$ & $55(21 \%)$ & $56(24 \%)$ & $111(22 \%)$ & $51(22 \%)$ & $63(23 \%)$ & $114(23 \%)$ \\
\hline $\begin{array}{l}\text { Previous taxane } \\
\text { treatment }\end{array}$ & $58(22 \%)$ & 52 (22\%) & $110(22 \%)$ & $62(27 \%)$ & $59(22 \%)$ & $121(24 \%)$ \\
\hline Previous bevacizumab & $39(15 \%)$ & $32(14 \%)$ & $71(14 \%)$ & $36(16 \%)$ & $43(16 \%)$ & 79 (16\%) \\
\hline
\end{tabular}


treatment

Time since start of first-

line therapy (to start of

second-line therapy)

$\begin{array}{lllllll}<9 \text { months } & 159(60 \%) & 123(53 \%) & 282(57 \%) & 148(65 \%) & 175(65 \%) & 323(65 \%) \\ \geq 9 \text { months } & 106(40 \%) & 109(47 \%) & 215(43 \%) & 79(35 \%) & 94(35 \%) & 173(35 \%)\end{array}$

Abbreviations: ASBI, Average Symptom Burden Index; CR, complete response; ECOG PS, Eastern Cooperative Oncology Group performance status; EGFR, epidermal growth factor receptor; HSB, high symptom burden; ITT, intent-to-treat; LSB, low symptom burden; PBO, placebo; PD, progressive disease; PR, partial response; RAM, ramucirumab; SD, stable disease. 
Table 3. Overlap in REVEL Aggressive or Refractory Disease Subgroups

\begin{tabular}{|c|c|c|c|c|}
\hline Patient Group & Overall, $\mathbf{N}$ & $\begin{array}{c}\text { Rapid } \\
\text { Progressor, }{ }^{\mathrm{a}} \mathrm{n}(\%)\end{array}$ & $\begin{array}{c}\text { Non-Rapid } \\
\text { Progressor, }{ }^{b} \mathbf{n}(\%)\end{array}$ & $P$-value \\
\hline High ASBI & 497 & $92(18.5)$ & $405(81.5)$ & 0.059 \\
\hline Low ASBI & 497 & $70(14.1)$ & $427(85.9)$ & \\
\hline Overall & 994 & $162(16.3)$ & $832(83.7)$ & \\
\hline Patient Group & Overall, $\mathrm{N}$ & Refractory, ${ }^{c}$ n (\%) & Nonrefractory, n (\%) & \\
\hline High ASBI & 497 & $164(33.0)$ & $333(67.0)$ & 0.008 \\
\hline Low ASBI & 497 & $126(25.4)$ & $371(74.6)$ & \\
\hline Overall & 994 & $290(29.2)$ & $704(70.8)$ & \\
\hline Patient Group & Overall, $\mathbf{N}$ & Refractory, ${ }^{c}$ n (\%) & Nonrefractory, n (\%) & \\
\hline Rapid progressora & 209 & $174(83.3)$ & $35(16.7)$ & $<0.001$ \\
\hline Non-rapid progressorb & 1044 & $186(17.8)$ & $858(82.2)$ & \\
\hline Overall & 1253 & $360(28.7)$ & $893(71.3)$ & \\
\hline
\end{tabular}

Abbreviation: ASBI, Average Symptom Burden Index.

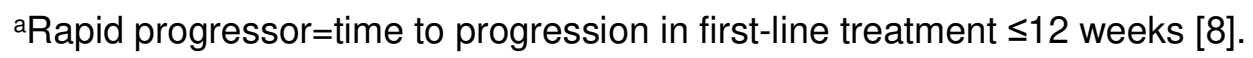

${ }^{\mathrm{b}}$ Non-rapid progressor=time to progression in first-line treatment $>12$ weeks [6].

${ }^{c}$ Refractory=best response to first-line treatment of progressive disease [7]. 
Table 4. Response by Baseline ASBI Subgroups

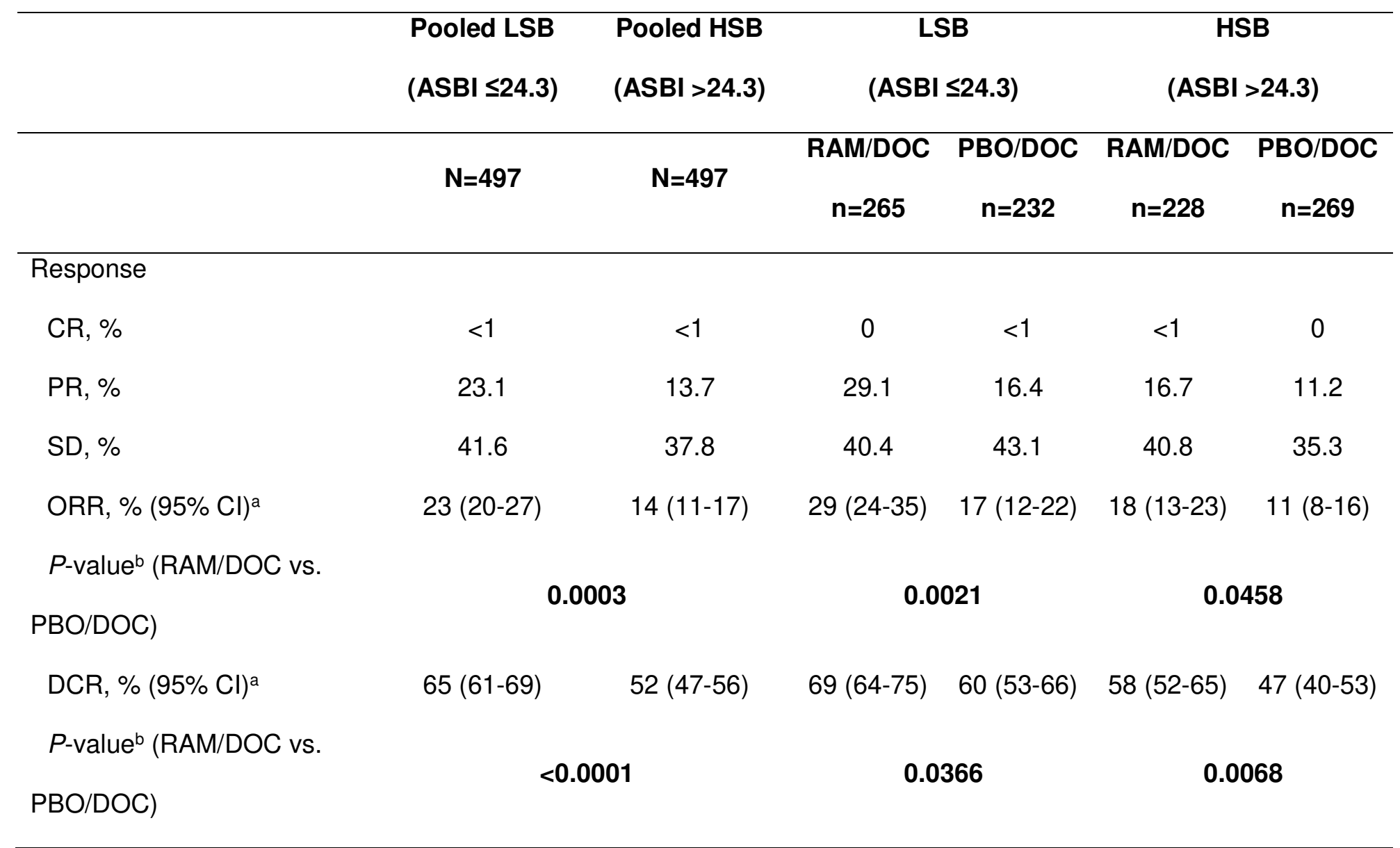

Abbreviations: ASBI, Average Symptom Burden Index; Cl, confidence interval; CR, complete response; DCR, disease control rate; DOC, docetaxel; HSB, high symptom burden; LSB, low symptom burden; ORR, objective response rate;PBO, placebo; PR, partial response; RAM, ramucirumab; SD, stable disease. 
Note: Bold $P$-values are significant. Treatment effect within each subgroup was significant at $P<0.05$; the interaction effect between treatment and subgroup was significant at $P<0.2$.

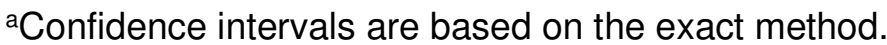

${ }^{\mathrm{b}} P$-value based on the Cochran-Mantel-Haenszel test adjusting for the stratification variables. 